\title{
ANALISIS PENGENDALIAN PERSEDIAAN MENGGUNAKAN FSN ANALYSIS PADA WAREHOUSE UKM ONLINE
}

\author{
Amri Yanuar \\ Program Studi D4 Logistik Bisnis, Politeknik Pos Indonesia \\ email: amriyanuar@poltekpos.ac.id
}

\begin{abstract}
Abstrak
Setiap organisasi harus mampu menyediakan produk agar selalu tersedia sehingga dapat memenuhi setiap permintaan yang masuk. Oleh karena itu, baik secara langsung ataupun tidak langsung organisasi harus memperhatikan dan mengelola persediaan secara baik. Karena manajemen persediaan penting bagi efektivitas dan efisiensi. Manajemen persediaan juga penting dalam mengendalikan persediaan yang harus disimpan untuk kebutuhan permintaan yang akan datang. Studi ini mengambil UKM yang telah menjalankan usahanya secara online dan memiliki gudang untuk menyimpan produk yang dijualnya lebih dari 7000 SKU. Berdasarkan observasi yang telah dilakukan, gudang yang menjalankan aktivitas keluar masuknya barang mengalami lamanya waktu pengerjaan order yang masuk karena pengelolaan produknya masih secara random, dan belum menerapkan model persediaan yang optimal untuk melakukan evaluasi persediaan barang jadinya sebagai parameter pengukuran. Analisis persediaan dan pengendalian menjadi hal yang tidak bisa dihindarkan oleh UKM. Untuk menjaga persediaan agar tidak lama keluar dari gudang harus dilakukan klasifikasi produk agar produk yang dikelola tidak menjadi produk yang dapat menghambat kapasitas penyimpanan sehingga tidak menjadi optimal. Metode FSN analysis dapat digunakan untuk menilai statistik dari produk. Ketika hasilnya dapat ditentukan secara akurat, maka akan menjadi sangat penting dalam menentukan tingkat persediaan dari setiap produk yang dikelola
\end{abstract}

\section{Kata Kunci: Pengendalian Persediaan, FSN Analysis}

\section{PENDAHULUAN}

Trend era digitalisasi memberikan dampak yang sangat signifikan terhadap industri baik jasa maupun manufaktur. Hal ini juga menjadi perhatian bagi para pelaku usaha skala kecil dan menengah yang mulai beralih dari konvensional menjadi online. Kementerian Koperasi dan Usaha Kecil Menengah mengeluarkan data bahwa sebanyak 3.79 juta pelaku usaha mikro, kecil, dan menengah dalam melakukan penjualan produknya sudah memanfaatkan berbagai macam platform online [1].

Jika dilihat dari berbagai produk yang dijual oleh pelaku usaha kecil dan menengah, terdapat beberapa kategori produk yang angka penjualannya tinggi seperti yang dapat dilihat pada gambar berikut;

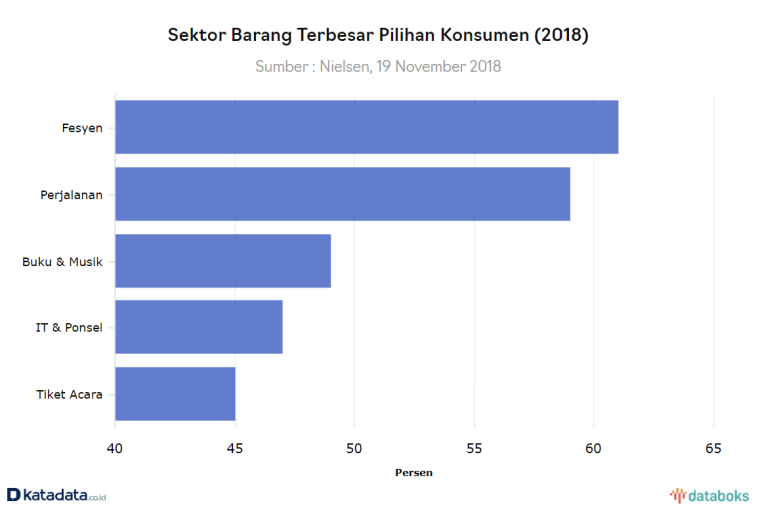

Lima produk yang menjadi pilihan konsumen diantaranya $61 \%$ produk fesyen, perjalanan $59 \%$, buku dan music $49 \%$, IT dan ponsel $47 \%$, dan terakhir sebesar $45 \%$ untuk produk tiket acara [2]. 
Ketika angka penjualan meningkat, setiap organisasi harus mampu menyediakan produk agar selalu tersedia sehingga dapat memenuhi setiap permintaan yang masuk. Oleh karena itu, baik secara langsung ataupun tidak langsung organisasi harus memperhatikan dan mengelola persediaan secara baik. Karena manajemen persediaan penting bagi efektivitas dan efisiensi. Manajemen persediaan juga penting dalam mengendalikan persediaan yang harus disimpan untuk kebutuhan permintaan yang akan datang. Manajemen persediaan memiliki tujuan untuk menyeimbangkan agar stok yang disimpan lebih ekonomis, yaitu persediaan yang disimpan tidak terlalu banyak [3].

Studi ini mengambil UKM yang telah menjalankan usahanya secara online dan memiliki gudang untuk menyimpan produk yang dijualnya lebih dari 7000 SKU. Berdasarkan observasi yang telah dilakukan, gudang yang menjalankan aktivitas keluar masuknya barang mengalami lamanya waktu pengerjaan order yang masuk karena pengelolaan produknya masih secara random, dan belum menerapkan model persediaan yang optimal untuk melakukan evaluasi persediaan barang jadinya sebagai parameter pengukuran.

Artikel membahas mengenai teknik manajemen persediaan untuk UKM Online menggunakan FSN Analysis untuk memberikan rekomendasi pengelolaan barang jadi dengan mengelompokkan setiap produk sehingga dapat membantu kelancaran proses bisnis UKM. Tujuan dari studi ini adalah:

a. Untuk mempelajari dan memahami teknik pengendalian persediaan

b. Untuk menentukan klasifikasi persediaan di UKM online dapat di evaluasi dan dipahami menggunakan FSN Analysis.

\section{METODE PENELITIAN}

Langkah-langkah yang dilakukan adalah sebagai berikut:

a. Menentukan data persediaan produk, dimulai dari data persediaan awal, persediaan masuk, dan pengeluaran produk. Kemudian tahap pengerjaannya sebagai berikut:

b. Menentukan persediaan awal, merupakan persediaan pada setiap awal periode pengamatan.

c. Menentukan persediaan akhir, merupakan persediaan produk yang tersisa pada setiap akhir periode pengamatan. Persediaan awal didapat dari persediaan produk yang tersisa di akhir periode sebelumnya. Jumlah persediaan akhir dihitung menggunakan rumus:

$$
P a k=P a w+P m s-P p k
$$

$$
\begin{array}{ll}
\text { dimana: } & \\
\text { Pak } & =\text { Persediaan akhir } \\
\text { Paw } & =\text { Persediaan awal } \\
\text { Pms } & =\text { barang masuk } \\
\text { Ppk } & =\text { barang yang dipakai }
\end{array}
$$

d. Menghitung nilai rata-rata persediaan, merupakan nilai rata-rata persediaan produk pada setiap periode pengamatan. Nilai rata-rata persediaan dihitung menggunakan rumus:

$$
\begin{aligned}
\operatorname{Prt}= & \frac{P a w+P a k}{2} \\
& \text { dimana: } \\
& \text { Prt }=\text { Persediaan Rata-rata }
\end{aligned}
$$

e. Menghitung Turn Over Ratio (TOR) parsial, merupakan perputaran persediaan setiap periode berjalan. Nilai TOR parsial dihitung menggunakan rumus:

$$
\text { TORp }=\frac{P m k}{P r t}
$$

Dimana:

TORp = Perputaran persediaan parsial selama periode pengamatan

Pmk = pemakaian barang selama periode pengamatan

f. Menghitung lamanya waktu penyimpanan, adalah waktu rata-rata yang dialami setiap produk untuk mengalami penyimpanan di gudang. Lama waktu penyimpanan barang dapat dihitung menggunakan rumus:

$$
W s p=\frac{J h p}{T O R}
$$

Dimana:

Wsp = Lamanya waktu penyimpanan

Jhp = Jumlah hari selama periode pengamatan

g. Menghitung turn over ratio (TOR), merupakan rasio perputaran persediaan setiap selama satu tahun. Nilai TOR dapat dihitung dengan rumus:

$T O R=\frac{J h t}{W s p}$

dimana:

TOR $=$ Perputaran persediaan selama satu tahun

Jht $=$ Jumlah hari selama satu tahun

Pengelompokkan barang dengan FSN Analysis (Fast, Slow, and Non-moving) berdasarkan TOR, dengan kriteria sebagai berikut [4]:

Urutkan data berdasarkan nilai TOR yang tertinggi hingga yang terendah.

Menentukan klasifikasi F (TOR $>3), \mathrm{S}(3 \leq \mathrm{TOR} \leq 1)$, N $($ TOR $<1)[4]$.

\section{HASIL DAN PEMBAHASAN}

\subsection{Pengumpulan Data}

Data yang digunakan pada penelitian ini didapat dari hasil observasi kepada UKM, pengumpulan data berupa; nama barang, persediaan awal, penerimaan, dan pengeluaran. 
Terdapat delapan produk yang di analisis selama satu tahun dimulai dari periode Juni 2019 hingga Mei 2020.

Tabel 1. Data Persediaan Item Oxford

\begin{tabular}{ccccc}
\hline & \multicolumn{4}{c}{ Item OXFORD } \\
\cline { 2 - 5 } Periode & $\begin{array}{c}\text { Persediaan } \\
\text { Awal }\end{array}$ & Penerimaan & Pengeluaran & $\begin{array}{c}\text { Persediaan } \\
\text { akhir }\end{array}$ \\
\hline Jun-19 & 285 & 150 & 46 & 389 \\
Jul-19 & 389 & 150 & 80 & 459 \\
Aug-19 & 459 & 150 & 119 & 490 \\
Sep-19 & 490 & 150 & 91 & 549 \\
Oct-19 & 549 & 150 & 97 & 602 \\
Nov-19 & 602 & 150 & 92 & 660 \\
Dec-19 & 660 & 150 & 89 & 721 \\
Jan-20 & 721 & 150 & 207 & 664 \\
Feb-20 & 664 & 150 & 180 & 634 \\
Mar-20 & 634 & 150 & 439 & 345 \\
Apr-20 & 345 & 150 & 176 & 319 \\
May-20 & 319 & 150 & 469 & 0 \\
Total & $\mathbf{6 1 1 7}$ & $\mathbf{1 8 0 0}$ & $\mathbf{2 0 8 5}$ & $\mathbf{5 8 3 2}$ \\
\hline
\end{tabular}

Tabel 2. Data Persediaan Item Boots

\begin{tabular}{ccccc}
\hline & \multicolumn{4}{c}{ Item BOOTS } \\
\cline { 2 - 5 } Periode & $\begin{array}{c}\text { Persediaan } \\
\text { Awal }\end{array}$ & Penerimaan & Pengeluaran & $\begin{array}{c}\text { Persediaan } \\
\text { akhir }\end{array}$ \\
\hline Jun-19 & 500 & 700 & 541 & 659 \\
Jul-19 & 659 & 700 & 291 & 1068 \\
Aug-19 & 1068 & 700 & 738 & 1030 \\
Sep-19 & 1030 & 700 & 693 & 1037 \\
Oct-19 & 1037 & 700 & 982 & 755 \\
Nov-19 & 755 & 700 & 676 & 779 \\
Dec-19 & 779 & 700 & 630 & 849 \\
Jan-20 & 849 & 700 & 593 & 956 \\
Feb-20 & 956 & 700 & 618 & 1038 \\
Mar-20 & 1038 & 700 & 537 & 1201 \\
Apr-20 & 1201 & 700 & 511 & 1390 \\
May-20 & 1390 & 700 & 1894 & 196 \\
Total & $\mathbf{1 1 2 6 2}$ & $\mathbf{8 4 0 0}$ & $\mathbf{8 7 0 4}$ & $\mathbf{1 0 9 5 8}$ \\
\hline
\end{tabular}

Tabel 3. Data Persediaan Item Flatshoes

\begin{tabular}{ccccc}
\hline & \multicolumn{4}{c}{ Item FLATSHOES } \\
\cline { 2 - 5 } Periode & $\begin{array}{c}\text { Persediaan } \\
\text { Awal }\end{array}$ & Penerimaan Pengeluaran & $\begin{array}{c}\text { Persediaan } \\
\text { akhir }\end{array}$ \\
\hline Jun-19 & 1723 & 3000 & 1147 & 3576 \\
Jul-19 & 3576 & 3000 & 1686 & 4890 \\
Aug-19 & 4890 & 3000 & 1845 & 6045 \\
Sep-19 & 6045 & 3000 & 2239 & 6806 \\
Oct-19 & 6806 & 3000 & 2563 & 7243 \\
Nov-19 & 7243 & 3000 & 2110 & 8133 \\
Dec-19 & 8133 & 3000 & 3423 & 7710 \\
Jan-20 & 7710 & 3000 & 3356 & 7354 \\
Feb-20 & 7354 & 3000 & 3075 & 7279 \\
Mar-20 & 7279 & 3000 & 2763 & 7516 \\
Apr-20 & 7516 & 3000 & 2577 & 7939 \\
May-20 & 7939 & 3000 & 5850 & 5089 \\
Total & $\mathbf{7 6 2 1 4}$ & $\mathbf{3 6 0 0 0}$ & $\mathbf{3 2 6 3 4}$ & $\mathbf{7 9 5 8 0}$ \\
\hline
\end{tabular}

Tabel 4. Data Persediaan Item Sneakers

\begin{tabular}{ccccc}
\hline \multirow{2}{*}{ Periode } & \multicolumn{4}{c}{ Item SNEAKERS } \\
\cline { 2 - 5 } & $\begin{array}{c}\text { Persediaan } \\
\text { Awal }\end{array}$ & Penerimaan & Pengeluaran & $\begin{array}{c}\text { Persediaan } \\
\text { akhir }\end{array}$ \\
\hline Jun-19 & 3215 & 5000 & 3077 & 5138 \\
Jul-19 & 5138 & 5000 & 3902 & 6236 \\
Aug-19 & 6236 & 5000 & 4760 & 6476 \\
Sep-19 & 6476 & 5000 & 4650 & 6826 \\
Oct-19 & 6826 & 5000 & 5417 & 6409 \\
Nov-19 & 6409 & 5000 & 4722 & 6687 \\
Dec-19 & 6687 & 5000 & 6738 & 4949 \\
Jan-20 & 4949 & 5000 & 5238 & 4711 \\
Feb-20 & 4711 & 5000 & 5863 & 3848 \\
Mar-20 & 3848 & 5000 & 5499 & 3349 \\
Apr-20 & 3349 & 5000 & 3461 & 4888 \\
May-20 & 4888 & 5000 & 7296 & 2592 \\
Total & $\mathbf{6 2 7 3 2}$ & $\mathbf{6 0 0 0 0}$ & $\mathbf{6 0 6 2 3}$ & $\mathbf{6 2 1 0 9}$ \\
\hline
\end{tabular}

Tabel 5. Data Persediaan Item Heels

\begin{tabular}{|c|c|c|c|c|}
\hline \multirow[b]{2}{*}{ Periode } & \multicolumn{4}{|c|}{ Item HEELS } \\
\hline & $\begin{array}{c}\text { Persediaan } \\
\text { Awal }\end{array}$ & Penerimaan & Pengeluaran & $\begin{array}{c}\text { Persediaan } \\
\text { akhir }\end{array}$ \\
\hline Jun-19 & 3245 & 3000 & 1905 & 4340 \\
\hline Jul-19 & 4340 & 3000 & 2564 & 4776 \\
\hline Aug-19 & 4776 & 3000 & 2816 & 4960 \\
\hline Sep-19 & 4960 & 3000 & 2864 & 5096 \\
\hline Oct-19 & 5096 & 3000 & 3232 & 4864 \\
\hline Nov-19 & 4864 & 3000 & 3418 & 4446 \\
\hline Dec-19 & 4446 & 3000 & 3628 & 3818 \\
\hline Jan-20 & 3818 & 3000 & 3858 & 2960 \\
\hline Feb-20 & 2960 & 3000 & 3324 & 2636 \\
\hline Mar-20 & 2636 & 3000 & 3275 & 2361 \\
\hline Apr-20 & 2361 & 3000 & 2284 & 3077 \\
\hline May-20 & 3077 & 3000 & 4892 & 1185 \\
\hline Total & 46579 & 36000 & 38060 & 44519 \\
\hline
\end{tabular}

Tabel 6. Data Persediaan Item Platform

\begin{tabular}{ccccc}
\hline \multirow{2}{*}{ Periode } & \multicolumn{4}{c}{ Item PLATFORM } \\
\cline { 2 - 5 } & $\begin{array}{c}\text { Persediaan } \\
\text { Awal }\end{array}$ & Penerimaan & Pengeluaran & $\begin{array}{c}\text { Persediaan } \\
\text { akhir }\end{array}$ \\
\hline Jun-19 & 1240 & 1200 & 773 & 1667 \\
Jul-19 & 1667 & 1200 & 816 & 2051 \\
Aug-19 & 2051 & 1200 & 913 & 2338 \\
Sep-19 & 2338 & 1200 & 1214 & 2324 \\
Oct-19 & 2324 & 1200 & 1250 & 2274 \\
Nov-19 & 2274 & 1200 & 921 & 2553 \\
Dec-19 & 2553 & 1200 & 1413 & 2340 \\
Jan-20 & 2340 & 1200 & 1101 & 2439 \\
Feb-20 & 2439 & 1200 & 1266 & 2373 \\
Mar-20 & 2373 & 1200 & 1218 & 2355 \\
Apr-20 & 2355 & 1200 & 745 & 2810 \\
May-20 & 2810 & 1200 & 2345 & 1665 \\
Total & $\mathbf{2 6 7 6 4}$ & $\mathbf{1 4 4 0 0}$ & $\mathbf{1 3 9 7 5}$ & $\mathbf{2 7 1 8 9}$ \\
\hline
\end{tabular}


Tabel 7. Data Persediaan Item Sandal

\begin{tabular}{ccccc}
\hline \multirow{2}{*}{ Periode } & \multicolumn{4}{c}{ Item SANDAL } \\
\cline { 2 - 5 } & $\begin{array}{c}\text { Persediaan } \\
\text { Awal }\end{array}$ & Penerimaan & Pengeluaran & $\begin{array}{c}\text { Persediaan } \\
\text { akhir }\end{array}$ \\
\hline Jun-19 & 1545 & 2000 & 1066 & 2479 \\
Jul-19 & 2479 & 2000 & 1371 & 3108 \\
Aug-19 & 3108 & 2000 & 1615 & 3493 \\
Sep-19 & 3493 & 2000 & 2037 & 3456 \\
Oct-19 & 3456 & 2000 & 1890 & 3566 \\
Nov-19 & 3566 & 2000 & 1999 & 3567 \\
Dec-19 & 3567 & 2000 & 2324 & 3243 \\
Jan-20 & 3243 & 2000 & 1820 & 3423 \\
Feb-20 & 3423 & 2000 & 1887 & 3536 \\
Mar-20 & 3536 & 2000 & 1467 & 4069 \\
Apr-20 & 4069 & 2000 & 1523 & 4546 \\
May-20 & 4546 & 2000 & 5297 & 1249 \\
Total & $\mathbf{4 0 0 3 1}$ & $\mathbf{2 4 0 0 0}$ & $\mathbf{2 4 2 9 6}$ & $\mathbf{3 9 7 3 5}$ \\
\hline
\end{tabular}

Tabel 8. Data Persediaan Item Backpack

\begin{tabular}{ccccc}
\hline Periode & \multicolumn{4}{c}{ Item BACKPACK } \\
\cline { 2 - 5 } & $\begin{array}{c}\text { Persediaan } \\
\text { Awal }\end{array}$ & Penerimaan & Pengeluaran & $\begin{array}{c}\text { Persediaan } \\
\text { akhir }\end{array}$ \\
\hline Jun-19 & 643 & 1000 & 525 & 1118 \\
Jul-19 & 1118 & 1000 & 679 & 1439 \\
Aug-19 & 1439 & 1000 & 654 & 1785 \\
Sep-19 & 1785 & 1000 & 710 & 2075 \\
Oct-19 & 2075 & 1000 & 880 & 2195 \\
Nov-19 & 2195 & 1000 & 1122 & 2073 \\
Dec-19 & 2073 & 1000 & 1377 & 1696 \\
Jan-20 & 1696 & 1000 & 1281 & 1415 \\
Feb-20 & 1415 & 1000 & 1021 & 1394 \\
Mar-20 & 1394 & 1000 & 1237 & 1157 \\
Apr-20 & 1157 & 1000 & 743 & 1414 \\
May-20 & 1414 & 1000 & 2388 & 26 \\
Total & $\mathbf{1 8 4 0 4}$ & $\mathbf{1 2 0 0 0}$ & $\mathbf{1 2 6 1 7}$ & $\mathbf{1 7 7 8 7}$ \\
\hline
\end{tabular}

Menghitung nilai rata-rata persediaan, merupakan nilai dari rata-rata persediaan produk yang terdapat pada setiap periode pengamatan. Nilai rata-rata persediaan ini dapat dihitung dengan persamaan (2), kemudian hasilnya dapat dilihat pada tabel 9 .

Tabel 9. Rata-rata Persediaan

\begin{tabular}{ccccccccc}
\hline & \multicolumn{7}{c}{ Rata-rata Persediaan } \\
\cline { 2 - 9 } Periode & $\begin{array}{c}\text { Item } \\
\text { OXFORD }\end{array}$ & $\begin{array}{c}\text { Item } \\
\text { BOOTS }\end{array}$ & $\begin{array}{c}\text { Item } \\
\text { FLATSHOES }\end{array}$ & $\begin{array}{c}\text { Item } \\
\text { SNEAKERS }\end{array}$ & $\begin{array}{c}\text { Item } \\
\text { HEELS }\end{array}$ & $\begin{array}{c}\text { Item } \\
\text { PLATFORM }\end{array}$ & $\begin{array}{c}\text { Item } \\
\text { SANDAL }\end{array}$ & $\begin{array}{c}\text { Item } \\
\text { BACKPACK }\end{array}$ \\
\hline Jun-19 & 337 & 579,5 & 2649,5 & 4176,5 & 3792,5 & 1453,5 & 2012 & 880,5 \\
Jul-19 & 424 & 863,5 & 4233 & 5687 & 4558 & 1859 & 2793,5 & 1278,5 \\
Aug-19 & 474,5 & 14099 & 5467,5 & 6356 & 4868 & 2194,5 & 3300,5 & 1612 \\
Sep-19 & 519,5 & 1033,5 & 6425,5 & 6651 & 5028 & 2331 & 3474,5 & 1930 \\
Oct-19 & 575,5 & 896 & 7024,5 & 6617,5 & 4980 & 2299 & 3511 & 2135 \\
Nov-19 & 631 & 767 & 7688 & 6548 & 4655 & 2413,5 & 3566,5 & 2134 \\
Dec-19 & 690,5 & 814 & 7921,5 & 5818 & 4132 & 2446,5 & 3405 & 1884,5 \\
Jan-20 & 692,5 & 902,5 & 7532 & 4830 & 3389 & 2389,5 & 3333 & 1555,5 \\
Fe-20-20 & 649 & 997 & 7316,5 & 4279,5 & 2798 & 2406 & 3479,5 & 1404,5 \\
Mar-20 & 489,5 & 1119,5 & 7397,5 & 3598,5 & 2498,5 & 2364 & 3802,5 & 1275,5 \\
Apr-20 & 332 & 1295,5 & 7727,5 & 4118,5 & 2719 & 2582,5 & 4307,5 & 1285,5 \\
May-20 & 159,5 & 793 & 6514 & 3740 & 2131 & 2237,5 & 2897,5 & 720 \\
Total & 5974,5 & 11110 & 77897 & 62420,5 & 45549 & 26976,5 & 39883 & 18095,5 \\
\hline
\end{tabular}

Menghitung (TOR) turn over ratio parsial, merupakan rasio perputaran stok pada setiap periode berjalan. Dapat dihitung menggunakan persamaan (3), dan hasilnya dapat dilihat pada tabel 10 .
Tabel 10. TOR Partial

\begin{tabular}{|c|c|c|c|c|c|c|c|c|}
\hline \multirow[b]{2}{*}{ Periode } & \multicolumn{8}{|c|}{ TOR Partial } \\
\hline & $\begin{array}{l}\text { Item } \\
\text { OXFORD }\end{array}$ & $\begin{array}{c}\text { Item } \\
\text { BooTs }\end{array}$ & $\begin{array}{c}\text { Item } \\
\text { FLATSHOES }\end{array}$ & $\begin{array}{c}\text { Item } \\
\text { SNEAKERS }\end{array}$ & $\begin{array}{l}\text { Item } \\
\text { HEELS }\end{array}$ & $\begin{array}{c}\text { Item } \\
\text { PLATFORM }\end{array}$ & $\begin{array}{c}\text { Item } \\
\text { SANDAL }\end{array}$ & $\begin{array}{c}\text { Item } \\
\text { BACKPACK }\end{array}$ \\
\hline Jun-19 & 0,14 & 0,93 & 0,43 & 0,74 & 0,50 & 0,53 & 0,53 & 0,60 \\
\hline Jul-19 & 0,19 & 0,34 & 0,40 & 0,69 & 0,56 & 0,44 & 0,49 & 0,53 \\
\hline Aug-19 & 0,25 & 0,70 & 0,34 & 0,75 & 0,58 & 0,42 & 0,49 & 0,41 \\
\hline Sep-19 & 0,18 & 0,67 & 0,35 & 0,70 & 0,57 & 0,52 & 0,59 & 0,37 \\
\hline Oct-19 & 0,17 & 1,10 & 0,36 & 0,82 & 0,65 & 0,54 & 0,54 & 0,41 \\
\hline Nov-19 & 0,15 & 0,88 & 0,27 & 0,72 & 0,73 & 0,38 & 0,56 & 0,53 \\
\hline Dec-19 & 0,13 & 0,77 & 0,43 & 1,16 & 0,88 & 0,58 & 0,68 & 0,73 \\
\hline Jan-20 & 0,30 & 0,66 & 0,45 & 1,08 & 1,14 & 0,46 & 0,55 & 0,82 \\
\hline Feb-20 & 0,28 & 0,62 & 0,42 & 1,37 & 1,19 & 0,53 & 0,54 & 0,73 \\
\hline Mar-20 & 0,90 & 0,48 & 0,37 & 1,53 & 1,31 & 0,52 & 0,39 & 0,97 \\
\hline Apr-20 & 0,53 & 0,39 & 0,33 & 0,84 & 0,84 & 0,29 & 0,35 & 0,58 \\
\hline May-20 & 2,94 & 2,39 & 0,90 & 1,95 & 2,30 & 1,05 & 1,83 & 3,32 \\
\hline
\end{tabular}

Menghitung lamanya waktu penyimpanan, yaitu waktu rata-rata yang dialami oleh produk ketika disimpan di gudang hingga produk tersebut keluar. Lamanya waktu penyimpanan setiap produk dapat dihitung menggunakan persamaan (4), kemudian hasilnya dapat dilihat pada tabel 11.

Tabel 11. Waktu Penyimpanan

\begin{tabular}{ccccccccc}
\hline & \multicolumn{7}{c}{ Wsp (Waktu Penyimpanan) } \\
\cline { 2 - 9 } Periode & $\begin{array}{c}\text { Item } \\
\text { OXFORD }\end{array}$ & $\begin{array}{c}\text { Item } \\
\text { BOOTS }\end{array}$ & $\begin{array}{c}\text { Item } \\
\text { FLATSHOES }\end{array}$ & $\begin{array}{c}\text { Item } \\
\text { SNEAKERS }\end{array}$ & $\begin{array}{c}\text { Item } \\
\text { HEELS }\end{array}$ & $\begin{array}{c}\text { Item } \\
\text { PLATFORM }\end{array}$ & $\begin{array}{c}\text { Item } \\
\text { SANDAL }\end{array}$ & $\begin{array}{c}\text { Item } \\
\text { BACKPACK }\end{array}$ \\
\hline Jun-19 & 183,15 & 26,78 & 57,75 & 33,93 & 49,77 & 47,01 & 47,19 & 41,93 \\
Jul-19 & 143,10 & 80,12 & 67,79 & 39,35 & 48,00 & 61,51 & 55,01 & 50,84 \\
Aug-19 & 115,63 & 41,22 & 85,94 & 38,72 & 50,13 & 69,70 & 59,27 & 71,48 \\
Sep-19 & 142,72 & 37,28 & 71,75 & 35,76 & 43,89 & 48,00 & 42,64 & 67,96 \\
Oct-19 & 160,19 & 24,64 & 74,00 & 32,98 & 41,60 & 49,66 & 50,16 & 65,51 \\
Nov-19 & 178,33 & 29,50 & 94,73 & 36,05 & 35,41 & 68,13 & 46,39 & 49,45 \\
Dec-19 & 201,72 & 33,59 & 60,17 & 22,45 & 29,61 & 45,02 & 38,09 & 35,58 \\
Jan-20 & 90,33 & 41,09 & 60,60 & 24,90 & 23,72 & 58,60 & 49,45 & 32,79 \\
Feb-20 & 90,14 & 40,33 & 59,48 & 18,25 & 21,04 & 47,51 & 46,10 & 34,39 \\
Mar-20 & 28,99 & 54,20 & 69,61 & 17,01 & 19,84 & 50,46 & 67,39 & 26,81 \\
Apr-20 & 49,05 & 65,92 & 77,96 & 30,94 & 30,95 & 90,13 & 73,54 & 44,98 \\
May-20 & 8,84 & 10,89 & 28,95 & 13,33 & 11,33 & 24,81 & 14,22 & 7,84 \\
\hline
\end{tabular}

Menghitung (TOR) turn over ratio, merupakan rasio perputaran persediaan setiap selama satu tahun. TOR dapat dihitung menggunakan persamaan (5), dan hasilnya dapat dilihat pada tabel 12 .

Tabel 12. TOR

\begin{tabular}{ccccccccc}
\hline & \multicolumn{7}{c}{ TOR } \\
\cline { 2 - 9 } Periode & $\begin{array}{c}\text { Item } \\
\text { OXFORD }\end{array}$ & $\begin{array}{c}\text { Item } \\
\text { BOOTS }\end{array}$ & $\begin{array}{c}\text { Item } \\
\text { FLATSHOES }\end{array}$ & $\begin{array}{c}\text { Item } \\
\text { SNEAKERS }\end{array}$ & $\begin{array}{c}\text { Item } \\
\text { HEELS }\end{array}$ & $\begin{array}{c}\text { Item } \\
\text { PLATFORM }\end{array}$ & $\begin{array}{c}\text { Item } \\
\text { SANDAL }\end{array}$ & $\begin{array}{c}\text { Item } \\
\text { BACKPACK }\end{array}$ \\
\hline Jun-19 & 1,99 & 13,63 & 6,32 & 10,76 & 7,33 & 7,76 & 7,74 & 8,71 \\
Jul-19 & 2,55 & 4,56 & 5,38 & 9,28 & 7,60 & 5,93 & 6,63 & 7,18 \\
Aug-19 & 3,16 & 8,85 & 4,25 & 9,43 & 7,28 & 5,24 & 6,16 & 5,11 \\
Sep-19 & 2,56 & 9,79 & 5,09 & 10,21 & 8,32 & 7,60 & 8,56 & 5,37 \\
Oct-19 & 2,28 & 14,82 & 4,93 & 11,07 & 8,77 & 7,35 & 7,28 & 5,57 \\
Nov-19 & 2,05 & 12,37 & 3,85 & 10,12 & 10,31 & 5,36 & 7,87 & 7,38 \\
Dec-19 & 1,81 & 10,87 & 6,07 & 16,26 & 12,33 & 8,11 & 9,58 & 10,26 \\
Jan-20 & 4,04 & 8,88 & 6,02 & 14,66 & 15,39 & 6,23 & 7,38 & 11,13 \\
Feb-20 & 4,05 & 9,05 & 6,14 & 20,00 & 17,34 & 7,68 & 7,92 & 10,61 \\
Mar-20 & 12,59 & 6,73 & 5,24 & 21,45 & 18,40 & 7,23 & 5,42 & 13,61 \\
Apr-20 & 7,44 & 5,54 & 4,68 & 11,80 & 11,79 & 4,05 & 4,96 & 8,11 \\
May-20 & 41,28 & 33,53 & 12,61 & 27,39 & 32,23 & 14,71 & 25,66 & 46,56 \\
\hline
\end{tabular}

Kriteria pengelompokkan barang dengan FSN analysis berdasarkan TOR dilihat dari F (TOR $>3)$, S $(3 \leq$ TOR $\leq$ 1), N (TOR $<1)$. Hasil perhitungan TOR pada tabel 12 , nilai TOR seluruh produk berada pada TOR $>3$, dapat disimpulkan produk-produk yang di analisa masuk ke dalam kelompok fast moving. 
Tabel 13. Data Kelompok Barang

\begin{tabular}{|c|c|c|c|c|c|c|c|c|}
\hline \multicolumn{9}{|c|}{ Data kelompok barang } \\
\hline & Oxford & Boots & Flatshoes & Sneakers & Heels & Platform & Sandal & Backpack \\
\hline $\begin{array}{l}\text { Rata-rata } \\
\text { Persediaan }\end{array}$ & 2873 & 2172,5 & 3481 & 2897,5 & 1707 & 3148,5 & 1818,5 & 720 \\
\hline TOR Partial & 9,46 & 18,43 & 6,89 & 8,39 & 23,28 & 5,85 & 6,60 & 17,52 \\
\hline $\begin{array}{l}\text { Waktu } \\
\text { Simpan }\end{array}$ & 38,57 & 19,81 & 52,94 & 43,53 & 15,68 & 62,44 & 55,31 & 20,83 \\
\hline TOR & 9,46 & 18,43 & 6,89 & 8,39 & 23,28 & 5,85 & 6,60 & 17,52 \\
\hline Kelompok & $\mathbf{F}$ & $\mathbf{F}$ & $F$ & $F$ & $F$ & $\mathbf{F}$ & $\mathbf{F}$ & $\mathbf{F}$ \\
\hline
\end{tabular}

Hasil perhitungan dan pengelompokkan barang yang dikelola oleh UKM dapat dilihat pada tabel 13, dimana terdapat 8 produk yang masuk kedalam kategori fast moving. Sehingga dengan hasil ini UKM dapat menentukan bahwa produk-produk ini sebagai prioritas utama dalam menjalankan proses bisnisnya.

\section{KESIMPULAN DAN SARAN}

Analisis persediaan dan pengendalian menjadi hal yang tidak bisa dihindarkan oleh UKM. Untuk menjaga persediaan agar tidak lama keluar dari gudang harus dilakukan klasifikasi produk agar produk yang dikelola tidak menjadi produk yang dapat menghambat kapasitas penyimpanan sehingga tidak menjadi optimal. Metode FSN analysis dapat digunakan untuk menilai statistik dari produk. Ketika hasilnya dapat ditentukan secara akurat, maka akan menjadi sangat penting dalam menentukan tingkat persediaan dari setiap produk yang dikelola.

\section{REFERENSI}

Kominfo.go.id, "Kemenkop UKM: 3,79 Juta UMKM Sudah Go Online," 2017. .

Katadata.id, " 5 Jenis Barang yang Paling Diburu Konsumen di E-Commerce," 2019. .

R. Nadkarni and A. Ghewari, "An Inventory Control Using ABC Analysis and FSN Analysis," Int. J. Eng. Bus. Enterp. Appl., vol. Vol. 16, no. No. 1, pp. 24-28, 2016.

D. Devarajan and M. S. Jayamohan, "Stock control in a Chemical Firm: Combined FSN and XYZ

Analysis," Procedia Technol., vol. 24, pp. 562567, 2016. 